\title{
Transformation of Chinese Government's Economic Function under Globalization
}

\author{
Chen Meixia \\ (School of Public Administration, Yunnan University of Finance and Economics \\ Kunming,P .R.China, 650221) \\ (yngcx@126.com)
}

\begin{abstract}
Encountering with the strain of economic globalization, the Chinese government should fully recognize and understand their responsibilities in this process. They should positively change the way of government's function, and fundamentally realize the transform of its economic function from "all-round" and "finiteness" orientation to the focus of "standardized service", so that the government can provide better service to the public. This article mainly analyses how the Chinese government readjusts its role in the economy globalization, especially how to realize its transformation of economic function, and discuss the opportunities and challenges that Chinese government faces under the economic globalization, and then introduce the practical pathway of this process.
\end{abstract}

Keywords: economic globalization; economic functions of government; market economy;public administration

\section{Introduction}

Since the 1990s, with the development of international cooperation on market and technology and the end of the Cold War, the global economic cooperation in various fields and levels has grown rapidly and reached a new height. As a result, the investment and trade regional liberalization, economic international, production integration and information globalization are surging forward.

The economic globalization links countries around the world more directly and closely between their economic developments. Thus, economy globalization and the development of new international industrial specialization deliver new opportunities for the regional economic development and the formation of Chinese competitive industries. Economic globalization is an inevitable result of economic development and technological progress.

\section{The effect of economic globalization for the} government's economic function

Development of economic globalization, no doubt, will further deepen the reform of China's market economy, standardize market economic order, expand the scope of market competition, and intensify the market competition, and promote the development of domestic regional economic integration. Under such background, government as the main facilitator of regional economic development must adjust its functions adequately, so that it can reflect the requirement of changing market. By improving the efficiency of government administration and services as well as the ability of adaption and utilization of international rules, the government can enhance the region's utmost market competitiveness.

\subsection{More shifts to the social public policy for government functions}

In the process of economic globalization's progress, the status and role of government has changed in the policy-making. In the past, government is the only maker of a country's economic system and policies, but under of economy globalization, the government has turned to the cooperator of policy-making. The role of industry organizations and other government agencies and market entities have gradually enhanced. With the deepening of economic globalization, the range of market extends from one 
country to the region and even the world, so does the scope of policy.

Therefore, if the government focus its policies more towards on education, social security, transportation, environmental protection, food safety and other social areas, it can improve the competitiveness of the region's economy indirectly.

\subsection{The enhanced trends of local decentralization reforms}

With the strengthening of China's reform, the status of the government is gradually increasing, as a result the local decentralization reform has become a worldwide trend. The reasons are as follows: First, the increasingly fierce international competition under the background of economy globalization, which needs to mobilize the enthusiasm of all levels of government to improve the country's competitiveness. Giving more power to local government helps to motivate them. Second, the national-level policies are restricted more and more by international rules but local policies are less influenced; Third, the future competitiveness of the national or regional economy mainly reflect on the regional industry aspect. To enhance regional industrial competitiveness, it is imperative for the government play a central role as the main organizer of the regional economic development

\subsection{The increasing expand of government's} regulation scopes and objects

With an expanding scope of government public policies, it is more easy for economic factors services and goods to flow cross borders in the process of globalization. Thus, it provides a better environment for various regions to attract external resources to address economic development issues in the regionalso economic globalization makes cross- region and international cooperation increasingly important. The surging of regional and international organizations has made their roles stronger and more complicated. All of these trends have demonstrated how important the regional and international co operations are. In general, economic globalization is rapidly expanding the government's scope of policy control, which is not limited to the regulation of its own region or country, but beyond the border and reaching the world.

\subsection{Government increasing emphasis on economic} security issues brought about by globalization

Economy globalization is a double-edged sword, as it brings not only tremendous new opportunities for national development, but also increasing risks. Development of economic globalization is achieved by closer links between productive activities market activities, products and industries of many regions. If there are any economic problems or unpredictable events of another region, it will have a negative impact on its own economy. As a result, it requires the government to improve the ability to respond to a variety of social and economic emergencies which raises higher demands to the transformation of government functions.

3. Challenges faced by transformation of government functions under the background of globalization

\subsection{New contents objectively required to add in} the transformation of government functions under the Globalization

In a market economy within a country, although government's functions are different due to the social, historical, culture and other conditions, their basic content is the governance on "market failure". Market economy of global economy and the 
globalization of market economy have brought out new content of market failures-- the world market failure, which means that there must be a corresponding new development of government functions. Therefore, the government must use mandatory administration and legal means instead of those undeveloped, incomplete or failure of the market mechanism. It also should rapidly develop and expand markets through the system innovations and supplies so as to promote economic growth and industrialization.

\subsection{The inefficient government intervention impedes the normal operation of the macro economy}

The main causes of inefficiency of government intervention are in the following areas: First, lack of competition. Since the purpose of government intervention is to remedy market failure, not for profit; and there is no competition between the various departments to provide public services, so it has inevitably led to inefficiencies. Second, there are no incentive measures to reduce costs. Activities of government departments mainly rely on fiscal spending to maintain, so it is difficult to calculate the costs, as a result it lacks benefit motivation to reduce costs and improve efficiency. Third, the government divisions are monopolistic. Government divisions can use this monopoly to improve service prices and lower quality of service, that administrative monopoly without competition will inevitably bring efficiency losses. Fourth, overstaffing of organization in Chinese government. The public financial support a big and redundant staff, which objectively affects the working efficiency.

\subsection{Weakening functions of government intervention in micro-economy}

China is the country from a planned economy to a market economy. Since it adopts a gradual transition, the current government functions still significantly carry some planned economic characteristics. According to the requirements of the WTO rules, the micro-economic functions of government intervention should be weakened and the administrative examination approval should be reduced, so as to separate government from stateowned enterprises management.

Thus, the government should carefully consider how to deal with the international division of labor, domestic coordination, regional balance, and take regional comparative advantages in order to maximize the benefits of its division in economic globalization. In the process of economy globalization, China's future economic development is inseparable with the transformation of government economic functions.

\section{Problems and Cause Analysis of transformation} of Chinese government functions in the process of globalization

Objectively, since the reform and opening up, the government's own reform is still lagging behind the economic system restructuring, intensity of the transformation is also less than that of institutions. There is still huge gap compared with the profound changes in the microscopic field. With the economy globalization and the trends of liberalization development, some deep-seated contradictions in reform are increasingly prominent, whether the transformation of government functions can be implemented as soon as possible will determine the success to resolve the deep-seated contradictions. 


\subsection{Growing "overstep" and "vacancy" problems} by ambiguous governmental functions

The "overstep" refers to government's action and management have gone beyond its authorized power and has directly undertaken the production and supply of private goods which could have been handled by market. The "vacancy" of government functions mainly refers to the absence of government in producing public goods and services. There are "vacuum" of government responsibility even in some public areas because of the government did not take its duties. The health care, pension, unemployment benefits and other social security services that should have been supplied the government lack adequate funds; the market economy order is not sound, competition rules is incomplete, and imperfect credit system is not perfect. Thus, the process of economy globalization, a competent government should perform its due responsibilities, so as to realize its functions better. Whether vacancy or overstep will result in deviation of government functions and impede the economic development and people's living standards.

\subsection{Ambiguity between government and state-} owned enterprise as well as their responsibilities.

The ambiguity between government and state-owned enterprises and the phenomena of government dislocation are still quite prominent. On the one hand, government is involved in too much of production and business activities, and intervene personnel arrangements and internal management, so the government functions, some extent, have replaced the enterprises and market's functions and becoming "approval economy." A very important reason for this situation is unclear role of government. The party organizations at all levels intervene too much to the government affairs, which is the fundamental cause of the failure of government functions' transformation.

\subsection{Directly over-intervene of government to microeconomicoperations especially state-owned enterprises}

The current Chinese government is both social and economic manager and the owner of state-owned enterprises. It still has considerable influence on the micro-economy, especially on the operation of stateowned enterprises. Some government institutions still take direct intervention in the control of state-owned enterprises. From the perspective of public choice theory, the government often plays a role of the "economic man" who peruses "maximum profit ". Such role allows government assumed a large number of economic construction functions which should be performed by companies. As a result, faced with such a huge temptation, it is difficult for government to voluntarily give up the power and interest, which leads to the slow reform of stateowned enterprise and long delayed transformation of government functions.

\subsection{Weakening the government's public service functions}

With some political and economic power continues to be "decentralized" and widely dispersed, some local government departments are beginning to form interest groups to seek interest. When the local government formulates policies, regulations, plans and development strategies, or when there are some conflicts between the regional and sections' interests and the public and global interests, some choices and decisions betray the public and global interests driven by the interests of sectors and regions. Serious consequences of chasing the local and departmental interests could be the "weakening of their public service functions or even the entire section and 
systemic corruption of entire industry, public authority descends to the tool of some special individual sectors and industries to seek interests, which cause government's functions even weaker.

\section{The practical path for government functions'} transformation under the background of globalization

For China, the opportunity of economy globalization is that development could further utilize international economic resources. The challenge is that if the shackles of the old system, the lagging economic system and the long-term market imperfections can not be overcome as soon as possible, not only it is difficult to attract the international economic resources but also it would drain the domestic ones. In this sense, competition among countries and regions are seemingly the competition for global economic resources, in deeply, it is the competition of market effectiveness and public environment level. Therefore promoting the government reform and the transformation of government economic functions is crucial for China to share the economic benefits of globalization.

\subsection{Keep up the effort to separate enterprise from} government management and properly handle the relationship among government, market and enterprises

In the market economy, the government is the main entity of macro-control, under this control, market play a fundamental role in the allocation of resources, enterprises are the main entities of competition in the market and create economic growth in this process, these three parts are independent and coordinated so as to construct the effective market mechanism. The role of government is to make up for market defect or market failure, and resolve those issues that can not be solved by the market solely and create a favorable environment for enterprise development. Therefore, the key to adjust the relationship between government, enterprises and the market is to reduce government's direct intervention in the economic and social life and it should focus their attention on creating a more efficient market. The government also should give authority to enterprises, markets, social organizations and intermediary agencies to deal the issues that is beyond government's management scope, let the market play a fuller basic role in allocating resources, so as to substantially give the power back to the enterprises and society, fully mobilize the enthusiasm of all aspects and strengthen the social economy vigor and efficiency of them.

5.2 Regulatory of government behavior, and strengthen its public service functions

Strengthening public service functions of government means to "pay more attention to public services, efforts to promote education, health, culture and other social undertakings and healthy development, establish and improve a fair and equitable benefit of all the people, a moderate level of public service system of sustainable development, and promote basic public services equalization. Under the market rules of the economy globalization, it is essential both to strengthen the government's macro-control ability, standardize the behavior of government functions, and to enhance its public service functions. Effective implementation of the government's public service functions refers to strengthening the socialist legal system, so that it can provide a broader, stable public service functions for the development of the country's economy. At the same time, the government's public information service capacity need to be intensified, the government should reinforce the release of public 
information, guiding the direction of social investment, improving and perfecting the basic laws of education, health care, social security and other aspects. It should clearly identify procedures, content range, quality standards and deadlines of the provided services and continue to enhance the regulatory of public services and promote the economy development.

\subsection{Identify the role of government and fully perform its functions}

In the socialist market economic system, the functions of the government's positioning can be summarized as: economic regulation, market supervision, social management and public services. In terms of economic regulation, the government should further improve and perfect the government's forecast, monitoring and early warn system of macroeconomic development, increase supervision on market, rectify market economic order, increase supervision of foreign economic activity, so as to improve its ability to read and respond to market signal thus ensuring national economic security. Under the background of economy globalization, the basic objective of the government's economic functions adjustment is to fully reflect market demands, and increase the domestic market's international competitiveness by improving efficiency of government management and service, and maximize its international competitive without violating international rules.

\subsection{Transform the through from the rule of man} to the rule of law

The market economy, in essence, is the rule of law economy, which requires the government policies to be dictated by law. Strengthening the rule of law in government policies is a way to ensure government to provide a fair market for enterprises. Under the age of globalization public administration is acting according to the rules, and resolving disputes and problems by negotiation based on the principle of justice, fairness, and mutual benefit. The Government should establish governance system that consistent with the market mechanism, and improve the market economic system, gradually make government practice in line with the law, and make government management model from personal authority to rule authority, so that the concept of government can transform from the rule by man to the rule by law.

\section{Conclusions}

Globalization is an endless process, therefore, the government's economic functions transformation cannot be achieved overnight. Rather, it is a vast systematic effort, which requires continuous efforts by many generations.

Government functions are based on objective needs of social and economic development, and subject to the exsisting political and economic system of society. Therefore whenever the social, economic and political and economic systems enter the stage of transformation, there are inevitably some requirements for the transformation government economic functions to meet the need of reform and development. The sign of success government transformation is fully playing the market forces in the appropriate time. The government needs to minimize the unnecessary intervention to the market, which can realize the transformation of government functions. 


\section{References}

(1) Cai Wenxia, Yu Wanlin.(2006). Economic Globalization and the Change of Regional Government Functions in China. Chinese Market, 4

(2) Wang Dongmei. Chinese Government Function Conversion under the Global Economic Background. (2007). Journal of Liaoning administration Institute, 2

(3) Yin Zhifang. Chinese Government Function Conversion under the Global Economic Overview. (2006). Journal of Branch The Party School of Shanxi Provincial committee of CPC, 2

(4) Zhang Zhenhong. (2007). Chinese Government Function Conversion Under The Global Background. Central China Teachers University

(5) Zhang Chengfu, Sun Baiying. (2009). Social Change and Government Innovation-Thirty Years of Reformation of Chinese Government. China Renmin University Press.

(6) Zhao Zhanjun. (2010). Change of government function and Market Value return: On market orientation of governmental function.

(7) Zhou Diankun. (2012). Misplacement andRectification of Government Economic Function. Economics, 3 